\title{
Overview of Systemic Therapy for Colorectal Cancer
}

\author{
Rachel A. Goodwin, M.D. ${ }^{1}$ and Timothy R. Asmis, M.D. ${ }^{1}$
}

Colorectal cancer (CRC) is the third most common cancer and second leading cause of death from cancer in North America. The authors provide an overview of the indications for both chemotherapy and targeted therapy, as well as discuss the efficacy and toxicity of systemic therapy. They highlight the key studies that lead to the initial historical use of fluorouracil (5FU) based chemotherapy in the adjuvant and metastatic setting, the recent adoption of $5 \mathrm{FU}$ plus leucovorin (LV) and oxaliplatin (FOLFOX) chemotherapy over $5 \mathrm{FU}$ when treating adjuvant patients, and the use of FOLFOX or $5 \mathrm{FU}$ plus LV and irinotecan (FOLFIRI) in metastatic patients. They also review the role of chemotherapy in treating rectal cancer and resectable liver metastatic disease. Future areas of research focus for systemic therapy of colorectal cancer are highlighted.

KEYWORDS: Chemotherapy, adjuvant therapy, targeted therapy, metastatic

Objectives: On completion of this article, the reader will have an overview of systemic therapy for colorectal cancer.

\section{EPIDEMIOLOGY}

Colorectal cancer (CRC) is a common and frequently fatal disease in North America. In the United States, 108,070 new cases of colon cancer and 40,740 new cases of rectal cancer were reported in 2008, with an estimated 49,960 deaths attributed to colorectal cancer. ${ }^{1}$ In Canada, there were $\sim 21,500$ new cases of CRC, with an estimated 8900 deaths in $2008 .^{2}$

\section{PERFORMANCE STATUS}

Fitness to undergo systemic chemotherapy is assessed using performance status. The efficacy of systemic therapy is limited to patients who have good performance status at therapy initiation. A patient with good performance status can independently care for his- or herself and is active for the majority of the day. A patient who spends more than half of waking hours confined to a bed or chair has a poor performance status. In general, patients with poor performance status experience more harm due to toxicity than benefit from systemic therapy. Patients with poor performance status are excluded from clinical trials, so benefit in this group has never been established. Efforts should focus on improving ambulation, nutrition, and pain control prior to initiating chemotherapy in patients with poor performance status.

\section{EFFICACY MEASURES}

Patients with metastatic CRC being treated with chemotherapy are followed closely to monitor efficacy.

\footnotetext{
${ }^{1}$ The Ottawa Hospital Regional Cancer Centre, Ottawa, Ontario, Canada.

Address for correspondence and reprint requests: Timothy $\mathrm{R}$. Asmis, M.D., The Ottawa Hospital Regional Cancer Centre, 501 Smyth Rd., Box 913, Ottawa, Ontario, Canada K1H 8L6 (e-mail: tasmis@ottawahospital.on.ca).
}

Colorectal Cancer; Guest Editor, Robin P. Boushey, M.D., Ph.D. Clin Colon Rectal Surg 2009;22:251-256. Copyright (C) 2009 by Thieme Medical Publishers, Inc., 333 Seventh Avenue, New York, NY 10001, USA. Tel: +1(212) 584-4662.

DOI 10.1055/s-0029-1242465. ISSN 1531-0043. 
There are standardized efficacy measures, such as the RECIST (response evaluation criteria in solid tumors) criteria, used as endpoints for large clinical trials. A partial response is defined as a $30 \%$ decrease in the longest dimension of each measurable tumor deposit, using unidimentional, or RECIST criteria. ${ }^{3}$ A complete response is complete disappearance of all clinically detectable disease. The response rate $(\mathrm{RR})$ is the percentage of patients who meet either a partial or complete response. Measures used to determine the duration of treatment benefit include: (1) progression-free survival (PFS), which is the time from the start of treatment to the date the disease worsens; (2) disease-free survival (DFS), which is the length of time patients are free of disease after completion of curative treatment; and (3) overall survival (OS), which is the length of time patients are alive after diagnosis or initiation of treatment for metastatic disease.

\section{EARLY CLINICAL TRIALS}

Early adjuvant chemotherapy trials from 1950 to mid1980 were unsuccessful in improving overall survival over surgery alone likely due to small sample size and the use of chemotherapy that would be considered today as ineffective against colon cancer. The first trial that showed an overall survival advantage after surgical resection with chemotherapy was the National Surgical Adjuvant Breast and Bowel Project (NSABP) C-01 trial. ${ }^{4}$ In this trial 1166 patients with Dukes B and C carcinoma of the colon were randomized to one of three arms postresection: no further treatment; MOF chemotherapy consisting of fluorouracil (5FU), semustine (methyl-1-[2-chloroethyl]-3-cyclohexyl-1-nitrosourea $[\mathrm{CCNU}]$ ), and vincristine (Oncovin ${ }^{\circledR}$; Eli Lilly \& Co., Indianapolis, IN); or Bacillus Calmette-Guerin (BCG). Patients treated with surgery alone had 1.29 times the risk of recurrence and 1.31 times the risk of dying as compared with those who were treated with MOF (5FU based) chemotherapy. Given the significant toxicity profile of MOF including secondary leukemias, attempts were made to combine $5 \mathrm{FU}$ with other less toxic drugs. The most successful of these was leucovorin (LV). NSABP C-03 trial randomized 1081 Dukes B and C patients to either MOF or 5FU plus leucovorin postsurgery. The 3-year DFS (73\% versus $64 \%, p=0.004)$ and OS $(84 \%$ versus $77 \%$, $p=0.003)$ was superior for the 5FU/LV arm. Until early 2000, 5FU/LV was the standard of care in North America for adjuvant chemotherapy postsurgical resection. ${ }^{5}$ The benefit of $5 \mathrm{FU}$ in the metastatic setting has also been proven. A landmark trial conducted by Scheithauer et $\mathrm{al}^{6}$ found that overall survival was significantly improved (11 months versus 5 months, $p=0.006)$ for patients on 5FU-based chemotherapy compared with supportive care alone.

\section{POSTOPERATIVE MANAGEMENT OF STAGE II AND III DISEASE}

Postoperative, or "adjuvant," systemic therapy has become standard for stage III colon cancer. Adjuvant therapy should also be strongly considered in stage II patients. It is generally recommended for any medically fit patient with stage II cancer with unfavorable factors, including colonic perforation, poorly differentiated histology, colonic obstruction, lymphovascular invasion, or inadequately sampled lymph nodes. ${ }^{7}$ The optimal choice of adjuvant chemotherapy has recently changed from a 6-month course of 5FU-based chemotherapy alone to a 6-month course of infusional $5 \mathrm{FU}$ plus $\mathrm{LV}$ and oxaliplatin (FOLFOX) based on a large trial of adjuvant systemic therapy for resected stage II or III colon cancer. ${ }^{8}$ This trial demonstrated an increase in disease-free survival at 3 years from 72.9 to $78.2 \%$ $(p=0.002)$ with addition of oxaliplatin to FU/LV. Five-year disease-free survival remained significant (HR: $0.80 ; p=0.003$ ) and at 6 years there was an overall survival benefit for stage III patients $(68.3 \%$ versus 72.9\%). ${ }^{9}$ Toxicities were comparable between the two groups, with the exception that oxaliplatin is associated with a much higher rate of paresthesia: $12.4 \%$ versus $0.2 \%$ grade 3 (serious) toxicity. This neurotoxicity persisted at a grade 3 level in $1.1 \%$ of treated patients at one-year of follow-up.

\section{CHEMOTHERAPY FOR METASTATIC DISEASE}

Approximately $20 \%$ or more of patients with CRC initially present with metastatic disease (mCRC). Approximately $35 \%$ of patients who present with stage III, $20 \%$ of patients with stage II, and 5 to $10 \%$ of patients with stage I cancer eventually relapse and subsequently die from mCRC. The most common sites of metastases are the liver, lung, peritoneum, and retroperitoneum.

Many advances have occurred recently in the treatment of $\mathrm{mCRC}$. Active agents, in addition to the original $5 \mathrm{FU}$, that have been approved by the Food \& Drug Administration (FDA) for mCRC include irinotecan, capecitabine, oxaliplatin, bevacizumab, cetuximab, and panitumumab. The goals of systemic therapy of $\mathrm{mCRC}$ include palliation of symptoms, prolongation of life, and in selected cases of liver-only metastases, tumor regression to facilitate surgical resection of these metastases. The median survival of a patient with $\mathrm{mCRC}$ has improved during the last decade from less than 1 year, with only $5 \mathrm{FU}$-based therapy, to $\sim 2$ years, with multiagent systemic therapy.

$5 \mathrm{FU}$, often modified by LV, has been clinically used for half a century ${ }^{10}$ as a standard agent for mCRC. This was the only available agent until 1996, when irinotecan was approved. Over the last decade, 
chemotherapies such as oxaliplatin and capecitabine and targeted agents such as bevacizumab, cetuximab, and panitumumab have been approved. 5FU blocks the enzyme thymidylate synthase (TS), which is essential for DNA synthesis. Leucovorin (LV), also known as folinic acid, enhances the antineoplastic effects of 5FU. Both LV $(\mathrm{FOL}=$ folinic acid $)$ and $5 \mathrm{FU}(\mathrm{F}=$ fluorouracil) $\mathrm{can}$ be combined with irinotecan (IRI) or oxaliplatin (OX) with the treatment acronyms FOLFIRI or FOLFOX, respectively. These alternative treatments consist of administration of a bolus of $5 \mathrm{FU}, \mathrm{LV}$, and either oxaliplatin or irinotecan. The patient is then sent home with a 2-day infusion of low-dose 5FU, administered by a small, lightweight, portable pump, usually worn on a belt or shoulder strap, infused through a centrally placed catheter. The patient or health care provider can simply disconnect the catheter after the 2-day infusion. Capecitabine is an oral fluoropyrimidine with a similar mechanism of action and similar efficacy as 5FU.

Irinotecan is a derivative of camptothecin, found in Camptotheca acuminata, a plant native to China. It potently inhibits topoisomerase I, an enzyme that facilitates the uncoiling and recoiling of DNA during replication by cleaving one strand and subsequently reattaching that strand. Oxaliplatin is a platinum chemotherapy that inhibits DNA replication and transcription by forming inter- and intrastrand DNA adducts/ cross-links.

In patients with $\mathrm{mCRC}$, optimal chemotherapy consists of initial administration of a fluoropyrimidine and oxaliplatin or irinotecan (e.g., FOLFOX or FOLFIRI). Tournigand et $\mathrm{al}^{11}$ and Colucci et $\mathrm{al}^{12}$ performed randomized trials where patients received either FOLFIRI followed by FOLFOX, or vice versa. In the Tournigand et al study, FOLIRI was found to have a response rate (RR) of $56 \%$ and a 8.5 -month median progression free survival (mPFS), whereas FOLFOX had a RR of $54 \%$ and a mPFS of 8 months. Colucci et al found that FOLFIRI had a RR of $31 \%$ and FOLFOX had a RR of $34 \%$. Both regimens had a mPFS of 7 months. Both investigators concluded that both regimens had similar efficacy when used as first-line therapy. Therefore, either FOLFOX or FOLFIRI can be considered standard options for first-line treatment of $\mathrm{mCRC}$. These regimens are typically given with bevacizumab.

Bevacizumab is a monoclonal antibody that binds to vascular endothelial growth factor (VEGF) ligand to inhibit angiogenesis. Its antineoplastic effect is ascribed to regression of microvascular density, inhibition of neovascularization, and "normalization" of grossly abnormal tumor vasculature that permits more effective chemotherapy delivery to the tumor. The FDA recently approved bevacizumab in combination with $5 \mathrm{FU}$-based chemotherapy for $\mathrm{mCRC}$ based on findings that addition of bevacizumab to irinotecan, $5 \mathrm{FU}$, and $\mathrm{LV}$ for
mCRC improved PFS from 6.2 months to 10.6 months, improved the response rate from 35 to $45 \%{ }^{13}$ and improved overall survival from 15.6 to 20.3 months. Saltz et al found that the addition of bevacizumab to oxaliplatin-based chemotherapy significantly improved PFS from 8.0 to 9.3 months without an improvement in response rate. ${ }^{14}$ The finding of improved PFS without improved RR is common in trials of targeted therapy because the metastatic lesions can cavitate or have necrosis rather than regress. Recently, XELOX chemotherapy with or without bevacuzimab was found to be noninferior to FOLFOX with or without bevacuzimab. ${ }^{15}$ XELOX chemotherapy includes a combination of oral $5 \mathrm{FU}$ known as capecitabine or xeloda (XEL) plus oxaliplatin (OX). XELOX can be used as an alternative in patients who cannot tolerate FOLFOX side effects.

In 2004, the FDA approved cetuximab, the chimeric (human/mouse) monoclonal antibody targeting epidermal growth factor receptor (EGFR), for treatment of $\mathrm{mCRC}$ with irinotecan, and as a single agent for patients intolerant of irinotecan-based therapy. Early randomized trials showed benefit of cetuximab in previously treated $\mathrm{mCRC}$ patients. When cetuximab was combined with irinotecan in patients refractory to irinotecan-based chemotherapy, the response rate was $22.9 \%$ versus $10.8 \%$ for irinotecan alone. ${ }^{16}$ Among patients who failed previous lines of treatment, monotherapy with cetuximab was found to improve overall survival, PFS, and quality of life compared with best support care alone. ${ }^{17}$ Cetuximab causes an acneform rash on the face and upper body in more than $80 \%$ of patients. The rash is associated with improved survival. ${ }^{17}$

Although the FDA approved cetuximab for use in epidermal growth factor receptor (EGFR) expressing $\mathrm{mCRC}$, there is no evidence that the presence or absence of EGFR expression influences RR, and routine testing for this is unnecessary. K-ras mutations have been shown to predict response to cetuximab. The K-ras gene encodes a GTPase protein that is involved in cell signal transduction pathways. ${ }^{18}$ Wild-type (nonmutated) K-ras is found in normal cells. Approximately $40 \%$ of colorectal tumor cells have a mutated K-ras gene resulting in constitutively active protein and abnormal cell growth, proliferation, and differentiation. Evidence suggests there is no benefit in using cetuximab monotherapy in previously treated and untreated mCRC patients who have mutated K-ras tumors. Previously treated metastatic colorectal patients with mutated K-ras tumors did not benefit from cetuximab monotherapy, in contrast to patients with wild-type K-ras who had significantly improved overall survival and PFS. ${ }^{19}$ FOLIFIRI and cetuximab as first-line therapy in $\mathrm{mCRC}$ was found to reduce the risk of disease progression; however, the benefit was limited to patients with $\mathrm{K}$-ras wild-type tumors (HR 0.68, CI 0.50-0.94). ${ }^{18}$ 
In 2006, the FDA approved panitumumab, a monoclonal antibody to EGFR, which unlike cetuxi$\mathrm{mab}$, is fully humanized (not chimeric). It is indicated for patients with $\mathrm{mCRC}$ who have progressed on or are following 5FU, oxaliplatin, and irinotecan-containing regimens. In a large randomized trial of panitumumab versus best supportive care for $\mathrm{mCRC}$, a response rate of $10 \%$ was found. ${ }^{20}$ Like cetuximab, panitumumab causes an acneform skin rash. As a fully human monoclonal antibody, panitumumab has a lower risk of serious infusion reactions than the $3 \%$ rate observed with cetuximab. Similar to cetuximab, panitumumab monotherapy is more efficacious in patients with wild- rather than mutant-type K-ras tumors. In a randomized clinical trial of previously treated $\mathrm{mCRC}$ patients, median PFS and OS was significantly improved in the wild-type K-ras group compared with the mutant group. ${ }^{21} 17 \%$ of patients with wild-type $\mathrm{K}$-ras responded to treatment versus $0 \%$ of patients with mutant $\mathrm{K}$-ras. The relative activity of cetuximab versus panitumumab, as well as the relative activity of panitumumab when given with chemotherapy, is currently unknown.

\section{PERIOPERATIVE CHEMOTHERAPY FOR RESECTABLE LIVER METASTASES}

The standard of care for patients with resectable liver metastases as their only site of cancer spread is changing from previous surgical resection alone to a combination of perioperative chemotherapy and surgery based on a trial conducted by Nordlinger et al. ${ }^{22}$ This trial randomized patients with one to four potentially resectable liver metastases to either perioperative chemotherapy (six cycles of FOLFOX chemotherapy both pre- and postresection) or surgery alone. The authors concluded that perioperative chemotherapy reduced the risk of events such as progressive or recurrent disease and death by $25 \%$ in eligible and resected patients without increased severe, life-threatening toxicity. The results of this trial are controversial because when all randomized patients were included in the analysis only a trend and not significance in PFS favoring the chemotherapy arm was found.

\section{PREOPERATIVE CHEMORADIOTHERAPY FOR RECTAL CANCER}

Given the higher local recurrence rates and poorer overall survival of patients with rectal cancer, multimodality management is important. In the early 1990s, the standard of care following surgical resection for full thickness (T3-4) or lymph node positive rectal cancer was postoperative chemoradiotherapy as it was found to improve both local control and OS compared with surgery alone. ${ }^{23,24}$ Recently, preoperative chemoradiotherapy has become the treatment of choice for full thickness rectal cancers prior to total mesorectal excision based on a randomized clinical trial conducted by Sauer et al. Although this trial showed no difference in OS, improved local recurrence rates (6\% versus 13\%) were found for patients receiving preoperative 5FU-based chemoradiotherapy as compared with postoperative chemoradiotherapy. ${ }^{25}$ Preoperative 5FU chemoradiotherapy as compared with preoperative radiation alone also has been shown to improve local recurrence rates $(2.7 \%$ versus $14.6 \%){ }^{26}$

\section{NEW TARGETS}

Although new drug development takes years, targeted drug use can occur more quickly with advanced tests and will be a focus of future work. In addition, efforts will focus on identifying biomarkers that predict response to systemic therapy so that tailored therapy can be initiated.

With regards to the future of adjuvant systemic chemotherapy, microsatellite-instability (MSI) testing of tumor DNA may be used to identify which patients will benefit from additional therapy (i.e., predictive biomarker). ${ }^{27,28}$ Approximately $15 \%$ of colon cancers exhibit MSI commonly caused by loss of DNA mismatch-repair pathways. Tumors display short repeated nucleotide sequences called microsatellites secondary to frame-shift mutations and base-pair substitutions. Recent retrospective evidence demonstrated that adjuvant 5FU-based chemotherapy improved OS among patients with microsatellite-stable tumors. However, there was no benefit to those patients with high MSI. ${ }^{29}$ Ongoing trials are attempting to replicate these findings in a prospective manner.

The clinical benefit of cetuximab, a monoclonal antibody against EGFR, varies greatly depending on tumor biology: the greatest benefit is among patients with wild-type (nonmutated) K-ras tumors. In the metastatic setting, potential predictive biomarkers of interest include $\mathrm{K}$-ras, epiregulin, B-raf, PTEN, and $\mathrm{Pi} 3 \mathrm{~K}$. Jonker et al found that $\mathrm{mCRC}$ patients with both high epiregulin (ligand for EGFR) gene expression and $\mathrm{K}$-ras wild-type status had greater benefit from cetuximab therapy (HR for overall survival $0.43, p=0.001) .{ }^{30}$ In addition, loss of the tumor-suppressor gene PTEN ${ }^{31}$ and having mutated protein kinase $\mathrm{B}-\mathrm{raf}^{32}$ may predict for resistance to EGFR therapy such as cetuximab.

\section{CONCLUSION}

Over the past decade, the prevention and treatment of colorectal cancer has rapidly evolved. To implement evidence-based care a multidisciplinary team is required including surgeons, radiation and medical oncologists, as well as gastroenterologists, radiologists, pathologists, and primary care physicians. Unfortunately, despite improvements in surgical techniques and systemic therapy 
Table 1 Systemic Therapy for Colorectal Cancer

\begin{tabular}{|c|c|c|c|}
\hline Therapy & Mechanism of Action & Indications & Potential Common Toxicities \\
\hline $\begin{array}{l}\text { 5- Fluorouracil } \\
\qquad(5 F U)\end{array}$ & $\begin{array}{l}\text { Blocks the enzyme thymidylate } \\
\text { synthase (TS), which is } \\
\text { essential for DNA synthesis }\end{array}$ & $\begin{array}{l}\text { Multiple uses in combination with } \\
\text { other agents, both in the adjuvant } \\
\text { (postop) and palliative setting }\end{array}$ & $\begin{array}{l}\text { Gastrointestinal (nausea, } \\
\text { diarrhea) } \\
\text { Myelosuppression } \\
\text { Fatigue }\end{array}$ \\
\hline Capecitabine & $\begin{array}{l}\text { Blocks thymidylate synthase } \\
\text { (orally administered prodrug } \\
\text { converted to 5FU) }\end{array}$ & $\begin{array}{l}\text { Multiple uses in combination with } \\
\text { other agents, both in the adjuvant } \\
\text { (postop) and metastatic setting }\end{array}$ & $\begin{array}{l}\text { Gastrointestinal (nausea, } \\
\quad \text { diarrhea) } \\
\text { Myelosuppression } \\
\text { Fatigue } \\
\text { Palmar-plantar syndrome } \\
\text { (hand-foot syndrome) }\end{array}$ \\
\hline Oxaliplatin & $\begin{array}{l}\text { Inhibits DNA replication and } \\
\text { transcription by forming inter- } \\
\text { and intra-strand DNA } \\
\text { adducts/cross-links }\end{array}$ & $\begin{array}{l}\text { Used in combination with 5FU, } \\
\text { leucovorin (LV) (FOLFOX) in the } \\
\text { adjuvant (postop) and metastatic } \\
\text { setting }\end{array}$ & $\begin{array}{l}\text { Peripheral neuropathy } \\
\text { Gastrointestinal (nausea, } \\
\quad \text { diarrhea) } \\
\text { Fatigue } \\
\text { Myelosuppression } \\
\text { Hypersensitivity }\end{array}$ \\
\hline Irinotecan & $\begin{array}{l}\text { Inhibits topoisomerase I, an } \\
\text { enzyme that facilitates the } \\
\text { uncoiling and recoiling } \\
\text { of DNA during replication }\end{array}$ & $\begin{array}{l}\text { Used alone or in combination } \\
\text { with 5FU, LV (FOLFIRI) in the } \\
\text { metastatic setting }\end{array}$ & $\begin{array}{l}\text { Cholinergic (acute diarrhea) } \\
\text { Gastrointestinal (nausea, } \\
\quad \text { late diarrhea) } \\
\text { Fatigue } \\
\text { Myelosuppression } \\
\text { Alopecia }\end{array}$ \\
\hline Bevacizumab & $\begin{array}{l}\text { Monoclonal antibody which } \\
\text { binds to VEGF ligand }\end{array}$ & $\begin{array}{l}\text { Used in combination with either } \\
\text { FOLFOX or FOLFIRI in the } \\
\text { metastatic setting }\end{array}$ & $\begin{array}{l}\text { Hypertension } \\
\text { Arterial thrombotic events } \\
\text { Impaired wound healing } \\
\text { Gastrointestinal perforation }\end{array}$ \\
\hline Cetuximab & $\begin{array}{l}\text { Monoclonal antibody to EGFR } \\
\text { (chimeric) that blocks the } \\
\text { ligand-binding site }\end{array}$ & $\begin{array}{l}\text { Used with irinotecan or as a single } \\
\text { agent in the metastatic setting }\end{array}$ & $\begin{array}{l}\text { Acneform rash } \\
\text { Hypersensitivity } \\
\text { Hypomagnesemia } \\
\text { Fatigue }\end{array}$ \\
\hline Panitumumab & $\begin{array}{l}\text { Monoclonal antibody to EGFR } \\
\text { (fully humanized) that blocks } \\
\text { the ligand-binding site }\end{array}$ & $\begin{array}{l}\text { Used as a single agent in the } \\
\text { metastatic setting }\end{array}$ & $\begin{array}{l}\text { Acneform rash } \\
\text { Hypomagnesemia Fatigue }\end{array}$ \\
\hline
\end{tabular}

VEGF, vascular endothelial growth factor; EGFR, epidermal growth factor receptor.

CRC still remains the number two cause of cancer mortality in North America. Efforts to improve screening utilization by the general population are required to improve mortality and morbidity from CRC. Research advances in medical oncology will result in better understanding of tumor genetics and biology of the host. This will allow systemic therapy (Table 1) to be tailored to specific tumor molecular targets, while sparing toxicity to normal tissue. With these improvements in CRC care, hopefully it will become a rare disease but treatable with tailored medical treatments that are effective with low toxicity.

\section{REFERENCES}

1. Jemal A, Siegel R, Ward E, et al. Cancer statistics, 2008. CA Cancer J Clin 2008;58(2):71-96
2. Canadian Cancer Society/National Cancer Institute of Canada. Canadian Cancer Statistics 2008, Toronto, Canada

3. Therasse P, Arbuck SG, Eisenhauer EA, et al. New guidelines to evaluate the response to treatment in solid tumors. European Organization for Research and Treatment of Cancer, National Cancer Institute of the United States, National Cancer Institute of Canada. J Natl Cancer Inst 2000;92(3):205-216

4. Wolmark N, Fisher B, Rockette H, et al. Postoperative adjuvant chemotherapy or BCG for colon cancer: results from NSABP protocol C-01. J Natl Cancer Inst 1988; 80(1):30-36

5. Wolmark N, Rockette H, Fisher B, et al. The benefit of leucovorin-modulated fluorouracil as postoperative adjuvant therapy for primary colon cancer: results from National Surgical Adjuvant Breast and Bowel Project protocol C-03. J Clin Oncol 1993;11(10):1879-1887

6. Scheithauer W, Rosen H, Kornek GV, Sebesta C, Depisch D. Randomised comparison of combination chemotherapy 
plus supportive care with supportive care alone in patients with metastatic colorectal cancer. BMJ 1993;306(6880): $752-755$

7. Jonker DS, Maroun KJ. Adjuvant Systemic Chemotherapy for Stage II and III Colon Cancer Following Complete Resection: Guideline Recommendations. Cancer Care Ontario Evidence-Based Series\#2-29; Toronto: Cancer Care Ontario; 2008

8. André T, Boni C, Mounedji-Boudiaf L, et al; Multicenter International Study of Oxaliplatin/5-Fluorouracil/ Leucovorin in the Adjuvant Treatment of Colon Cancer (MOSAIC) Investigators. Oxaliplatin, fluorouracil, and leucovorin as adjuvant treatment for colon cancer. N Engl J Med 2004;350(23):2343-2351

9. De Gramont A, Boni C, Navarro M, et al. Oxaliplatin/5FU/LV in adjuvant colon cancer: Updated efficacy results of the MOSAIC trial, including survival, with a median followup of six years. Journal of Clinical Oncology, 2007 ASCO Annual Meeting Proceedings Part 1 2007;25(18S): Abstract 4007

10. Krueger GM, Alexander LL, Whippen DA, Balch CM. Arnoldus Goudsmit, MD, PhD: chemotherapist, visionary, founder of the American Society of Clinical Oncology, 19092005. J Clin Oncol 2006;24(24):4033-4036

11. Tournigand C, André T, Achille E, et al. FOLFIRI followed by FOLFOX6 or the reverse sequence in advanced colorectal cancer: a randomized GERCOR study. J Clin Oncol 2004;22(2):229-237

12. Colucci G, Gebbia V, Paoletti G, et al; Gruppo Oncologico Dell'Italia Meridionale. Phase III randomized trial of FOLFIRI versus FOLFOX4 in the treatment of advanced colorectal cancer: a multicenter study of the Gruppo Oncologico Dell'Italia Meridionale. J Clin Oncol 2005; 23(22):4866-4875

13. Hurwitz H, Fehrenbacher L, Novotny W, et al. Bevacizumab plus irinotecan, fluorouracil, and leucovorin for metastatic colorectal cancer. N Engl J Med 2004;350(23):2335-2342

14. Saltz L, Clarke S, Diaz-Rubio E, et al. Bevacizumab (Bev) in combination with XELOX or FOLFOX4: efficacy results from XELOX-1/NO16966, a randomized phase III trial in the first-line treatment of metastatic colorectal cancer (MCRC). Paper presented at: Gastrointestinal Cancers Symposium, American Society of Clinical Oncologists; July 19-21, 2007; Abstract 238; Orlando, FL

15. Cassidy J, Clarke S, Díaz-Rubio E, et al. Randomized phase III study of capecitabine plus oxaliplatin compared with fluorouracil/folinic acid plus oxaliplatin as first-line therapy for metastatic colorectal cancer. J Clin Oncol 2008;26(12): 2006-2012

16. Cunningham D, Humblet $\mathrm{Y}$, Siena S, et al. Cetuximab monotherapy and cetuximab plus irinotecan in irinotecanrefractory metastatic colorectal cancer. N Engl J Med 2004; 351(4):337-345

17. Jonker DJ, O'Callaghan CJ, Karapetis CS, et al. Cetuximab for the treatment of colorectal cancer. N Engl J Med 2007;357(20):2040-2048

18. Van Cutsem E, Köhne CH, Hitre E, et al. Cetuximab and chemotherapy as initial treatment for metastatic colorectal cancer. N Engl J Med 2009;360(14):1408-1417

19. Karapetis CS, Khambata-Ford S, Jonker DJ, et al. $\mathrm{K}$-ras mutations and benefit from cetuximab in advanced colorectal cancer. N Engl J Med 2008;359(17):17571765

20. Van Cutsem E, Peeters M, Siena S, et al. Open-label phase III trial of panitumumab plus best supportive care compared with best supportive care alone in patients with chemotherapy-refractory metastatic colorectal cancer. J Clin Oncol 2007;25:1658-1664

21. Amado RG, Wolf M, Peeters M, et al. Wild-type KRAS is required for panitumumab efficacy in patients with metastatic colorectal cancer. J Clin Oncol 2008;26(10):16261634

22. Nordlinger B, Sorbye H, Glimelius B, et al; EORTC Gastro-Intestinal Tract Cancer Group; Cancer Research UK; Arbeitsgruppe Lebermetastasen und-tumoren in der Chirurgischen Arbeitsgemeinschaft Onkologie (ALM-CAO); Australasian Gastro-Intestinal Trials Group (AGITG); Fédération Francophone de Cancérologie Digestive (FFCD). Perioperative chemotherapy with FOLFOX4 and surgery versus surgery alone for resectable liver metastases from colorectal cancer (EORTC Intergroup trial 40983): a randomised controlled trial. Lancet 2008;371(9617):1007-1016

23. Gastro-intestinal Tumor Study Group. Prolongation of the disease-free interval in surgically treated rectal carcinoma. N Engl J Med 1985;312:1465-1472

24. Krook JE, Moertel CG, Gunderson LL, et al. Effective surgical adjuvant therapy for high-risk rectal carcinoma. N Engl J Med 1991;324(11):709-715

25. Sauer R, Becker H, Hohenberger W, et al; German Rectal Cancer Study Group. Preoperative versus postoperative chemoradiotherapy for rectal cancer. N Engl J Med 2004; 351(17):1731-1740

26. Gérard JP, Conroy T, Bonnetain F, et al. Preoperative radiotherapy with or without concurrent fluorouracil and leucovorin in T3-4 rectal cancers: results of FFCD 9203. J Clin Oncol 2006;24(28):4620-4625

27. Gryfe R, Kim H, Hsieh ET, et al. Tumor microsatellite instability and clinical outcome in young patients with colorectal cancer. N Engl J Med 2000;342(2):69-77

28. Hemminki A, Mecklin JP, Järvinen $\mathrm{H}$, Aaltonen LA, Joensuu H. Microsatellite instability is a favorable prognostic indicator in patients with colorectal cancer receiving chemotherapy. Gastroenterology 2000;119(4):921-928

29. Ribic CM, Sargent DJ, Moore MJ, et al. Tumor microsatellite-instability status as a predictor of benefit from fluorouracil-based adjuvant chemotherapy for colon cancer. N Engl J Med 2003;349(3):247-257

30. Jonker DJ, Karpetis C, Harbison C, et al. High epiregulin (EREG) gene expression plus K-ras wild-type (WT) status as predictors of cetuximab benefit in the treatment of advanced colorectal cancer (ACRC): results from NCIC CTG CO.17A phase III trial of cetuximab versus best supportive care (BSC). J Clin Oncol 2009;27(15S): Abstract 4016

31. Loupakis F, Pollina L, Stasi I, et al. PTEN expression and KRAS mutations on primary tumors and metastases in the prediction of benefit from cetuximab plus irinotecan for patients with metastatic colorectal cancer. J Clin Oncol 2009;27(16):2622-2629

32. Di Nicolantonio F, Martini M, Molinari F, et al. Wild-type $\mathrm{BRAF}$ is required for response to panitumumab or cetuximab in metastatic colorectal cancer. J Clin Oncol 2008;26(35): $5705-5712$ 